\title{
RESOLUBILIDADE NA ESTRATÉGIA SAÚDE DA FAMÍLIA: UM ESTUDO DA TRAJETÓRIA TERAPÊUTICA DE USUÁRIAS DO SUS EM RELAÇÃO AO DIAGNÓSTICO E ESTADIAMENTO DA NEOPLASIA DE MAMA EM FEIRA DE SANTANA-BA.
}

\author{
Alberto Cezar Santos Almeida Filho'; ${ }^{1}$ Luciane Cristina Feltrin de Oliveira ${ }^{2}$; \\ 1. Bolsista PROBIC/CNPq, Graduando em Medicina, Universidade Estadual de Feira de Santana, e-mail: \\ beto.cezar@hotmail.com \\ 2. Orientadora, Departamento de Saúde, Universidade Estadual de Feira de Santana, e-mail: \\ feltrinlc@yahoo.com.br
}

PALAVRAS-CHAVE: Resolubilidade; Neoplasia de Mama; SUS.

\section{INTRODUÇÃO}

O conceito de resolubilidade pode ser entendido como a capacidade do sistema de apresentar uma resposta satisfatória ao usuário que busca atendimento a alguma necessidade de saúde, não se restringindo apenas a cura de doenças, mas também ao alívio ou minimização do sofrimento, a promoção e a manutenção da saúde (ASSIS et al, 2007).

De maneira geral, para aumentar a resolubilidade, também é necessário a adequação das ações à nova conjuntura demográfica brasileira. Essa nova conjuntura demográfica repercute no perfil epidemiológico de morbimortalidade, marcado pelo envelhecimento populacional e consequente diminuição proporcional da incidência de doenças infectocontagiosas e aumento das doenças crônico-degenerativas, como o câncer (ASSIS; JESUS, 2012).

O câncer de mama é o mais incidente entre as mulheres no mundo (ROSA; RADÜNZ, 2012). Dados brasileiros de 2015 demonstram incidência de 57 mil novos casos, dado que põe o câncer de mama como terceiro mais incidente na população brasileira geral e o primeiro entre as mulheres brasileiras (INCA, 2014).

É neste panorama que desde 2004, o Ministério da Saúde (MS) preconiza o exame clínico anual para mulheres assintomáticas a partir dos 40 anos de idade e a mamografia bienal para as mulheres entre 50 e 69 anos, com recomendações mais intensas para as que pertencem a grupos de alto risco (BRASIL, 2013).

Essas medidas de controle fazem parte dos principais meios para a obtenção de um dos objetivos específicos das Diretrizes Nacionais de Saúde da Mulher, a redução da morbimortalidade por câncer na população feminina. No entanto, a eficácia do controle dos cânceres de colo de útero e da mama depende de uma Atenção Básica à Saúde (ABS) qualificada e organizada, integrada com os demais níveis de atenção (BRASIL, 2013), uma vez que o acesso universal, igualitário e ordenado às ações e serviços de saúde começa pela porta de entrada do SUS, e, se completa na rede regionalizada e hierarquizada, de acordo com a complexidade do serviço, como previsto no Decreto $n^{\circ} 7.508$, de 2011. 


\section{METODOLOGIA}

Estudo de abordagem qualitativa, do tipo exploratório, que segundo Minayo (2010), ocorre num cenário natural que envolve a percepção da realidade cotidiana na busca do significado da ação social através das subjetividades dos participantes do processo investigado.

A escolha da abordagem qualitativa justificou-se por essa permitir uma compreensão mais aprofundada do objeto estudado, pois promove a ampreensão de diversos pontos de vista e a possibilidade do confronto ou concordância de opiniões dos sujeitos envolvidos no processo pesquisado.

Este estudo foi realizado na Unidade de Alta Complexidade em Oncologia (UNACON) do município de Feira de Santana. Os participantes do estudo foram mulheres em tratamento para Neoplásia Mamária na UNACON de Feira de Santana. Ao total, foram entrevistadas 9 mulheres $(n=9)$.

As técnicas de coleta de dados empregadas foram a entrevista semiestruturada e a observação sistemática. A entrevista semiestruturada foi utilizada, uma vez que alterna entre questões fechadas e abertas, sendo que as últimas permitem que os participantes discorram sobre o objeto de estudo, sem condições pré-fixadas pelo pesquisador (MINAYO, 2010).

O método de análise de dados escolhido foi a análise de conteúdo. A análise temática de conteúdo desdobra-se nas etapas pré-análise, exploração do material ou codificação e tratamento dos resultados obtidos/ interpretação (MINAYO, 2010).

Por se tratar de uma pesquisa envolvendo seres humanos, este estudo obedeceu à Resolução $\mathrm{n}^{\circ} 466$ de 12 de dezembro de 2012, do MS (BRASIL, 2012), que estabelece as diretrizes e normas regulamentadoras das pesquisas envolvendo seres humanos.

\section{RESULTADOS E/OU DISCUSSÃO}

Em nosso estudo, a maioria das mulheres entrevistadas não apresentava idade mínima recomendada para início do rastreamento do câncer de mama, e, apenas uma das participantes apresentada idade superior a 69 anos. Essa definição de uma dada faixa etária para rastreamento pelo SUS pode ser um dos motivos pelos quais as mulheres entrevistadas, em sua grande maioria, procuraram o serviço privado de atenção durante sua trajetória, como pode ser observado na fala de uma das usuárias:

Primeiro exame eu tive que pagar porque pela minha idade não faz pelo SUS, entendeu? Ai eu tive que pagar (U-2)

A queixa principal dessas usuárias eram nódulos presentes nos seios, e portanto já deveriam ter prioridade no atendimento em serviços públicos de diagnóstico. No entanto, por diversos motivos, grande parte das usuárias entrevistadas procuraram diretamente os serviços privados especializados de diagnóstico em mastologia.

Assim, a mulher ao perceber alterações em seu corpo, automaticamente faz suposições, momento esse vivenciado de modo único (COBERLLINI, 2001). Essa é uma etapa importante, uma vez que a atitude tomada nesta ocasião pode determinar o sucesso do tratamento. Neste momento, surgem perguntas difíceis de serem respondias e incertezas que devem ser enfrentadas junto com a doença e a mulher, muitas vezes se questiona porquê eu? (ARAÚJO; FERNANDES, 2008). Durante nosso estudo, foram encontradas diversas reações frente a suspeita diagnóstica pela presença de um nódulo mamário. Reações de medo frente a 
confirmação diagnóstica podem levar ao atraso do tratamento. Assim, cabe ressaltar que esses atrasos tanto podem ser decorrentes de dificuldades inerentes do sistema, quanto da própria reação frente a doença.

As dificuldades para ter acesso aos exames para o diagnóstico juntamente com a ideia de que o sistema público de saúde é demorado e não tem qualidade, principalmente no processo diagnóstico, esteve presente em algumas falas das usuárias. Esta ideia pode ser oriunda de experiências próprias negativas em relação ao serviço público de saúde ou de propagandas midiáticas negativas com o mesmo. Assim, o temor frente a uma doença que apresenta um estigma de mortalidade tão conhecido como o câncer de mama, impulsiona a usuárias a procurarem os serviços privados de saúde, mesmo enfrentando dificuldades financeiras.

\footnotetext{
Ah eu encontrei dificuldades em tudo né, porque na verdade eu não tenho condições não é? e ai tive que pedir ajuda a pessoas que eu conheço pra puder ver se conseguia os exames mais rápido.. (U-2).

Privado. Porque eu sempre eu fazia no público, só que a dificuldade e o tempo que leva, Como eu perdi muito tempo com isso, porque depois que vem essa mamografia, tanto protocolo e demora que a doença já avançou e a gente nunca vem esse resultado logo, isso pra mim foi .... (U-4)

Não, com certeza [IA DEMORAR], a gente sabe que demora, ai os exames eu paguei todos. Ai depois que eu terminei de pagar os exames o médico, me encaminhou pra aqui.
}

Tanto as Diretrizes para Detecção Precoce do Câncer de Mama no Brasil (2015) quanto no Caderno de Atenção Básica 13 - Controle dos Cânceres de Colo do Útero e da Mama (2013) enfatizam o papel da atenção primária no esclarecimento sobre os fatores de risco para o câncer de mama, assim como o correto encaminhamento para os serviços de mastologia, de forma a evitar a superestimação ou subestimação desse risco.

No entanto, na realidade estudada, visualizamos a descontinuidade das linhas de cuidado. Neste caso, as unidades básicas não contribuíram para a continuidade do cuidado, pois em muitos casos o processo de referência feito pelas unidades para a realização de exames diagnósticos e/ou para tratamento não aconteceu adequadamente.

Independente da etapa da trajetória terapêutica, a relativa demora para realização dos exames e início do tratamento tem impacto psicológico importante nas usuárias, assim como no prognóstico da doença (ARAÚJO; FERNANDES, 2008).

\section{CONSIDERAÇÕES FINAIS}

A maioria das pacientes entrevistadas encontrava-se fora da faixa etária indicada para rastreamento pelas propostas do Ministério da Saúde. No entanto, apresentaram como queixa principal para procura dos serviços médicos a presença de nódulos mamários. Cabe ressaltar que nas Diretrizes para Detecção Precoce do Câncer de Mama no Brasil (2015), do INCA, essa situação está contemplada e definida como referência urgente para serviços de diagnóstico mamário, a depender de algumas características da mulher, das alterações nos seios e do nódulo. Essa situação específica determina necessidade de consultas sem necessidade de agendamento e a inserção imediata dessas pacientes em agenda de demanda espontânea nos serviços. 
Os mais diversos sentimentos podem surgir frente a suspeita e ao próprio diagnóstico, desde o medo da confirmação diagnóstica até o estímulo ao enfrentamento da condição. Esses sentimentos são profundamente influenciados pelo contexto em que as usuárias se encontram, bem como o próprio diagnóstico pode influenciar esse contexto. $\mathrm{O}$ impacto do diagnóstico não afeta apenas as usuárias, mas também a dinâmica familiar e as complexas interações envolvidas nesta dinâmica.

Algumas usuárias não se sentiam verdadeiramente doentes. Devido a seu início insidioso as neoplasias apresentam esse caráter assintomático/oligossintomático que não condiz com o imaginário popular do "estar doente". Também devido à idade, algumas usuárias referiram não considerar o câncer de mama como suspeita inicial. Tal fato pode ser responsável pelo retardo da procura ao atendimento e também pelo agravamento do efeito psicológico do diagnóstico.

Ficou evidente que grande parte das pacientes entrevistadas teve que recorrer a serviços privados de atendimento para realização dos exames necessários para o diagnóstico, em algum momento da trajetória terapêutica. A procura por serviços privados foi motivada, em grande parte, pelas dificuldades de acesso ao serviço público e da necessidade de rapidez no processo diagnóstico, ficando assim evidente o ideário de que o sistema público de saúde é marcado pelo estigma do atraso e acesso segmentado.

Assim, o Câncer de Mama é um importante problema de Saúde Pública no Brasil, devido a sua alta incidência. $\mathrm{O}$ seu controle depende de um sistema de saúde estruturado em linhas de cuidado para o acompanhamento longitudinal das usuárias, desde o rastreamento e detecção precoce até o seu devido tratamento.

\section{REFERÊNCIAS}

ASSIS, M. M. A.; CERQUEIRA, E. M.; NASCIMENTO, M. A. A.; SANTOS, A. M.; JESUS, W. L. A. Atenção Primária à Saúde e sua articulação com a Estratégia Saúde da Família: construção política metodológica e prática. Revista de APS, Juiz de Fora, v. 10, p. 189-199, 2007.

ASSIS, M. M. A.; JESUS, W. L. A. Acesso aos serviços de saúde: abordagens, conceitos, políticas e modelo de análise. Ciênc. saúde coletiva. Rio de Janeiro, v. 17, n. 11, p. 28652875, Nov. 2012

BRASIL. Cadernos de Atenção Básica: Controle dos Cânceres do Colo do Útero e da Mama. Ministério da Saúde, Brasília, 2013.

CORBELLINI, V. L. Câncer de mama: encontro solitário com o temor do desconhecido. R. gaúcha Enferm., Porto Alegre, v.22, n.1, p.42-68, jan. 2001.

INCA. Diretrizes para a Detecção Precoce do Câncer de Mama no Brasil. Ministério da Saúde. Instituto Nacional de Câncer José Alencar Gomes da Silva (INCA). Rio de Janeiro. 2015.

MINAYO, M. C. de S. O desafio do conhecimento: Pesquisa qualitativa em saúde. 12. ed. São Paulo: Hucitec/Abrasco, 2010.

ROSA, L. M.; RADÜNZ, V. Taxa de sobrevida na mulher com câncer de mama: estudo de revisão. Texto Contexto Enferm, Florianópolis, n. 21, v. 4, p. 980-9, Out-Dez, 2012. 